\title{
Effect of Dietary Level of Protein or Methionine and Threonine on the Amino Acids and Catecholamines in Brain of Rats Fed a High Tyrosine Diet
}

\author{
Hidehiko YoKoGosHI ${ }^{1}$ \\ Laboratory of Nutritional Biochemistry, Department \\ of Agricultural Chemistry, Nagoya University, \\ Nagoya 464, Japan
}

(Received March 18, 1985)

\begin{abstract}
Summary When rats were fed a high tyrosine diet ( $5 \%$ in diet), plasma tyrosine, brain tyrosine, norepinephrine (NE), and 3-methoxy-4-hydroxyphenylethyleneglycol-sulfate $\left(\mathrm{MHPG}-\mathrm{SO}_{4}\right)$ were increased. The concentrations of brain tyrosine were directly correlated with those of plasma tyrosine and tyrosine ratios (tyrosine/large neutral amino acid (LNAA)) in plasma and brain. When rats were fed a high tyrosine diet with increasing amounts of the dietary protein, the contents of brain tyrosine and MHPG-SO ${ }_{4}$ decreased stepwise. By the supplementation of both methionine and threonine to the high tyrosine diet, the enhancement of brain tyrosine and MHPG-SO ${ }_{4}$ caused by tyrosine was significantly reduced. These results suggest that effects of tyrosine toxicity such as growth retardation or external pathological lesions may be due to the accelerated NE-turnover in the brain accompanied by the enhancement of brain tyrosine concentration. The supplemented methionine and threonine may cause an increase of tyrosine utilization, because methionine and threonine are the most limiting amino acids in casein, and also may inhibit the uptake of tyrosine into the brain via the blood-brain barrier.

Key Words tyrosine toxicity, methionine, threonine, brain, catecholamine, MHPG-SO
\end{abstract}

Growth depression and the development of external pathological lesions (paw lesions and cataract) caused by exposure to a high tyrosine-low protein diet in rats can be overcome by an extra addition of dietary protein(1-5). Effects of the supplementation of each amino acid or combinations of methionine and threonine on tyrosine toxicity have been reported (6-12), and some amino acids (glycine, cystine, threonine, methionine, tryptophan, or branched-chain amino acids) can reduce the toxic syndrome caused by excess tyrosine $(7,8,11,12)$. The addition of

\footnotetext{
1 横越英彦
} 
threonine to a high tyrosine diet alleviated growth retardation and the severity of symptoms, and lowered the tyrosine level in plasma, liver, and muscle (9-12). It was also known that the supplementation of both methionine and threonine to a high tyrosine-low protein diet improved growth and completely prevented the development of external toxic lesions $(13,14)$. Until now, the studies of tyrosine toxicity were almost all concentrated on the catabolism of tyrosine in liver.

Tyrosine is the substrate of protein synthesis and also is the substrate of catecholamine synthesis. Catecholamine biosynthesis is initiated by uptake of circulating tyrosine into neurons or chromaffin cells $(15)$ and its conversion to 3,4-dihydroxyphenylalanine (DOPA) by the enzyme tyrosine hydroxylase [EC 1.14.16.2](16). Circulating tyrosine can drive from dietary amino acids, hydroxylation of dietary phenylalanine, or tissue protein breakdown. Tyrosine administration enhances the urinary catecholamine excretion in rats $(17,18)$ and humans $(19,20)$, and also increases dopamine (DA) synthesis and release in lightactivated rat retina $(21,22)$. In the brain, the properties of the blood-brain barrier transport system which mediates the fluxes of tyrosine and other large neutral amino acids (LNAA: isoleucine, leucine, phenylalanine, valine, tryptophan) cause brain tyrosine levels to vary directly with the plasma tyrosine level, and inversely with the sum of the plasma concentrations of the other LNAA (23).

In this paper, I determined the correlation between tyrosine toxicity and brain catecholamines of rats fed a high tyrosine diet supplemented with extra proteins or methionine and threonine.

\section{MATERIALS AND METHODS}

Animals and diets. Male weanling Sprague-Dawley rats weighing about 50-60 g (Charles River Breeding Laboratories, Wilmington, MA) were housed in individual cages in our animal facility for 7 days, to adjust to the new environment. Food (Charles River Rat, Mouse and Hamster Maintenance Formula) was provided for a 5 -h period per day $(0900-1400 \mathrm{~h}$; dark period) and tap water ad libitum. The room temperature was maintained at $22^{\circ} \mathrm{C}$, and animals were exposed to 12-h cycles of light (2100-0900 h; Vita-Lite; Duro-Test Corp., North Bergen, NJ) and darkness (0900-2100 h). The basal diet consisted of 10\% vitamin-free casein; $4 \%$ mineral mixture; 2.2\% vitamin mixture (Bio-Serv, Inc., Frenchtown, NJ); $5 \%$ vegetable shortening fat (Crisco, Procter \& Gamble, Cincinnati, OH); and $78.8 \%$ dextrin. In other diets, casein and amino acids were added at the expense of carbohydrate. The high tyrosine diet contained $5 \%$ L-tyrosine and the amounts of supplemented amino acid were equivalent to the amino acid content in the $20 \%$ casein diet (12). All diets were mixed with the same weight of $5 \%$ agar solution to make agar-gel diets.

Experiment 1. Effect of additional protein on tissue amino acids and catecholamines in brain of rats fed a high tyrosine diet. Rats were meal-fed a $25 \%$ casein diet for 7 days and divided into six groups (six rats per group). Animals were meal- 
fed test diets containing 5,10 , and $30 \%$ casein with or without $5 \% \mathrm{~L}$-tyrosine for a 5 $\mathrm{h}$ period per day (0900-1400 h) for 2 days, and in the next morning, were provided test diets for 3-h (0900-1200 h), and then killed by decapitation. Their brains were immediately removed, frozen on dry ice, and stored at $-70^{\circ} \mathrm{C}$ until assay. Blood was collected from the cervical wound, and plasma samples were stored at $-20^{\circ} \mathrm{C}$ until assay. Amino acid concentrations in plasmas and brains were assayed by high performance liquid chromatography (HPLC; Waters Associates, Milford, MA) and by amino acid autoanalyzer (Beckman model 119C, Paloalto, CA), respectively. The catecholamines(NE, dopamine(DA), 3,4-dihydroxyphenyl acetic acid (DOPAC)) were purified over an alumina column and determined by reverse-phase HPLC with electrochemical detection(24). $\mathrm{MHPG}-\mathrm{SO}_{4}$ in brain was hydrolyzed enzymatically by sulfatase [EC 3.1.6.1] (Sigma, St. Louis, MO) to MHPG, which was then extracted into ethylacetate and assayed by the HPLC system. Tyrosine was measured fluorimetrically by the method of Waalkes et al.(25).

Experiment 2. Effect of individual amino acid supplements (LNAA) on tissue amino acids and catecholamines in brain of rats fed a high tyrosine diet. The experimental conditions were the same as in experiment 1 . The only difference was the test diet. Additional amounts of each amino acid to the $10 \%$ casein plus $5 \% \mathrm{~L}$ tyrosine diet were as follows: (\% of diet) L-methionine, 0.66; L-threonine, 0.90 ; Lvaline, 1.48; L-leucine, 2.02; L-phenylalanine, 1.16; L-tryptophan, 0.30 . These supplemented amounts of amino acids were selected to simulate their respective distribution in $20 \%$ casein (12). Amino acids, catecholamines, and $\mathrm{MHPG}-\mathrm{SO}_{4}$ were determined by the same methods as in experiment 1 .

Experiment 3. Effect of the combination of methionine and threonine on tissue amino acids and catecholamines of rats fed a high tyrosine diet. The experimental conditions were the same as in experiments 1 and 2 . Rats were meal-fed test diets containing $10 \%$ casein with $5 \%$ tyrosine, both $0.66 \%$ L-methionine and $0.90 \%$ Lthreonine, or these three amino acids for a 5-h period per day $(0900-1400 \mathrm{~h})$ for 2 days, and then the next morning were provided the test diet for 3-h (0900-1200 h) and killed by decapitation. Amino acids, catecholamines, and $\mathrm{MHPG}-\mathrm{SO}_{4}$ were determined by the same methods as in experiments 1 and 2 .

Statistical significance. The statistical significance of differences between values were determined by analysis of variance and Duncan's multiple range test (26).

\section{RESULTS}

\section{Effect of dietary protein level on tyrosine toxicity}

When rats were fed a high tyrosine diet with increasing amounts of the dietary protein, the differences of body weight gain and food intake during the experimental period were shortened as compared with those of each tyrosine-unsupplemented diet (in body weight, $5.5 \mathrm{~g} \rightarrow 3.3 \mathrm{~g} \rightarrow 1.4 \mathrm{~g}$; in food intake, $4.3 \mathrm{~g} \rightarrow 2.9 \mathrm{~g} \rightarrow 0.6 \mathrm{~g}$ ) (Table 1). As the dietary protein increased, the concentrations of almost all amino acids in Vol. 31 , No. 5,1985 


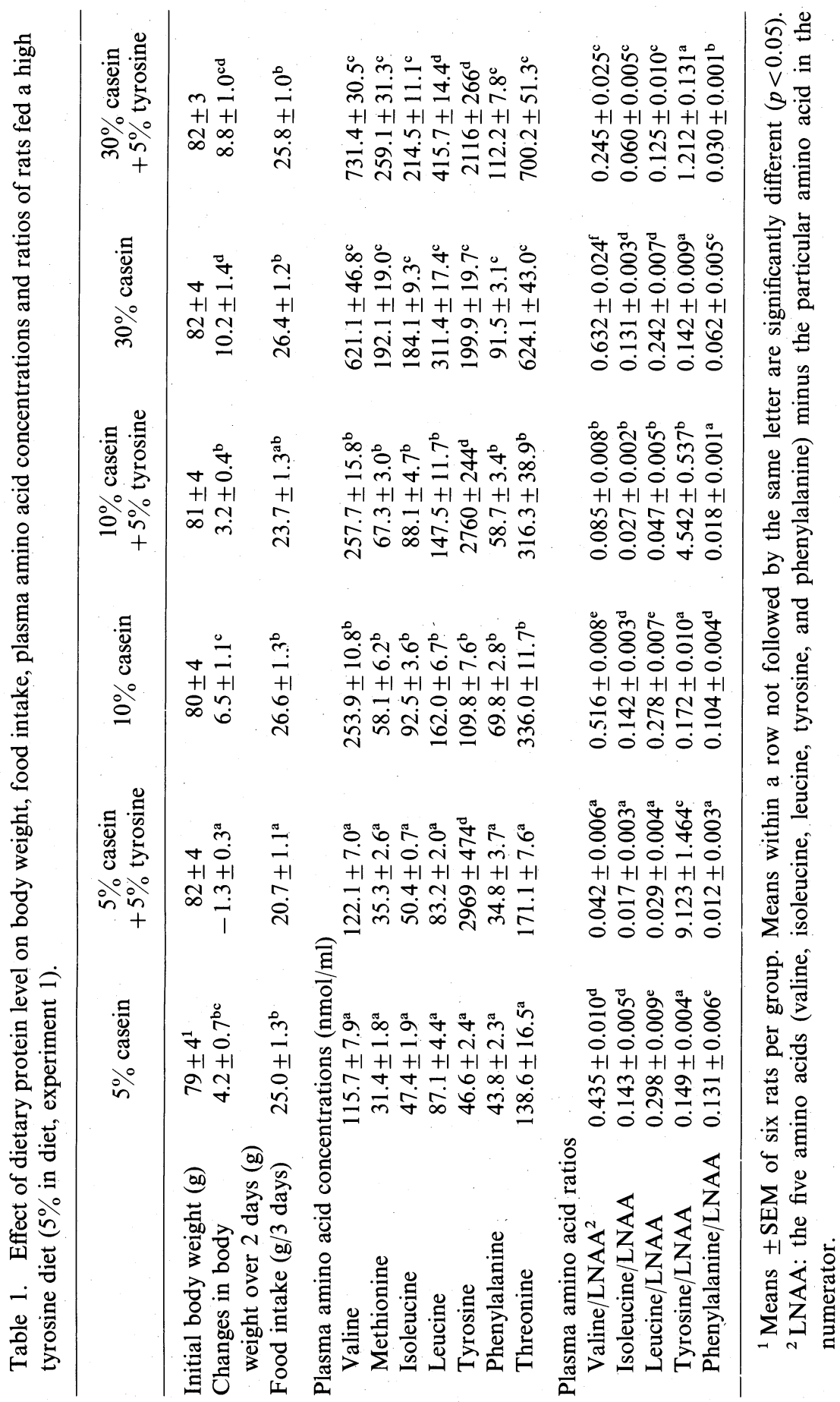

J. Nutr. Sci. Vitaminol. 


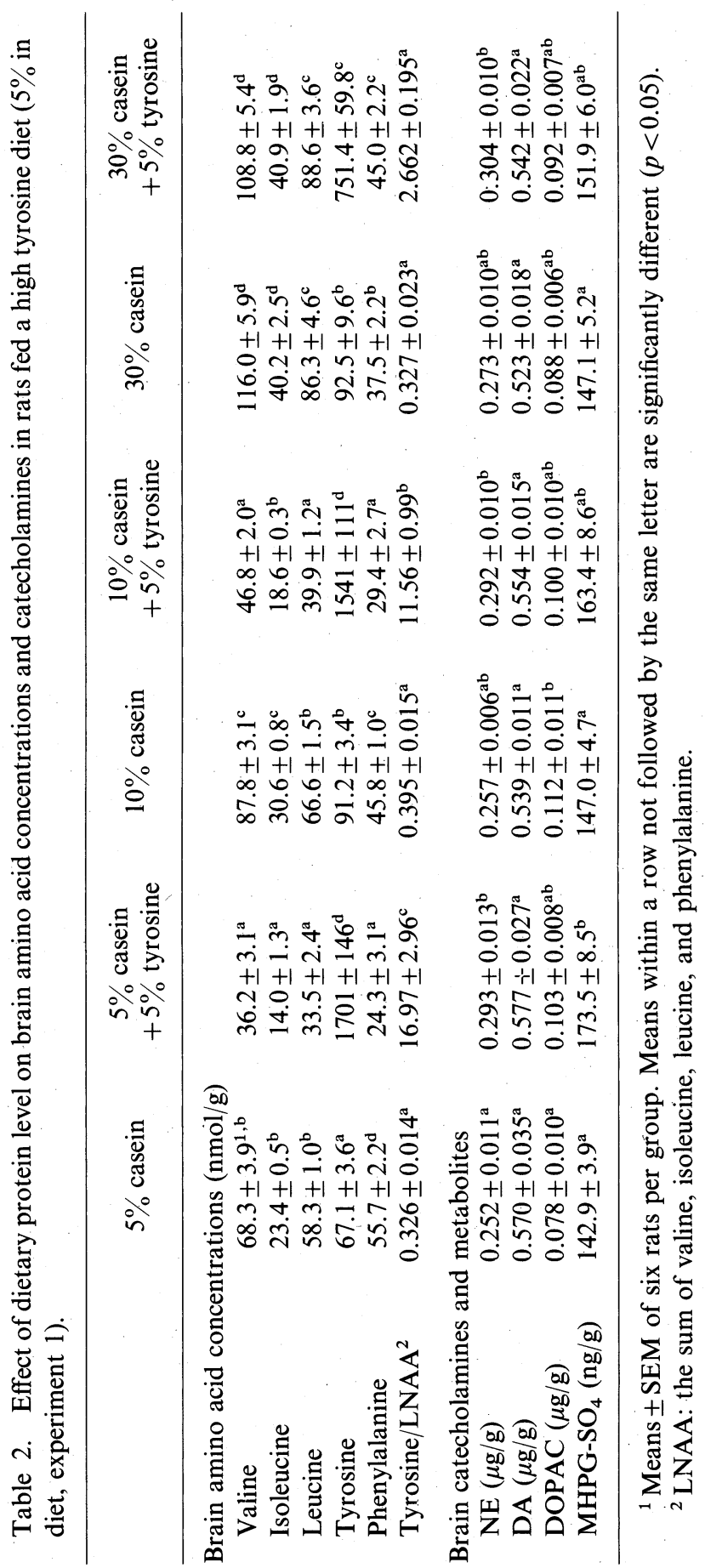

Vol. 31, No. 5, 1985 


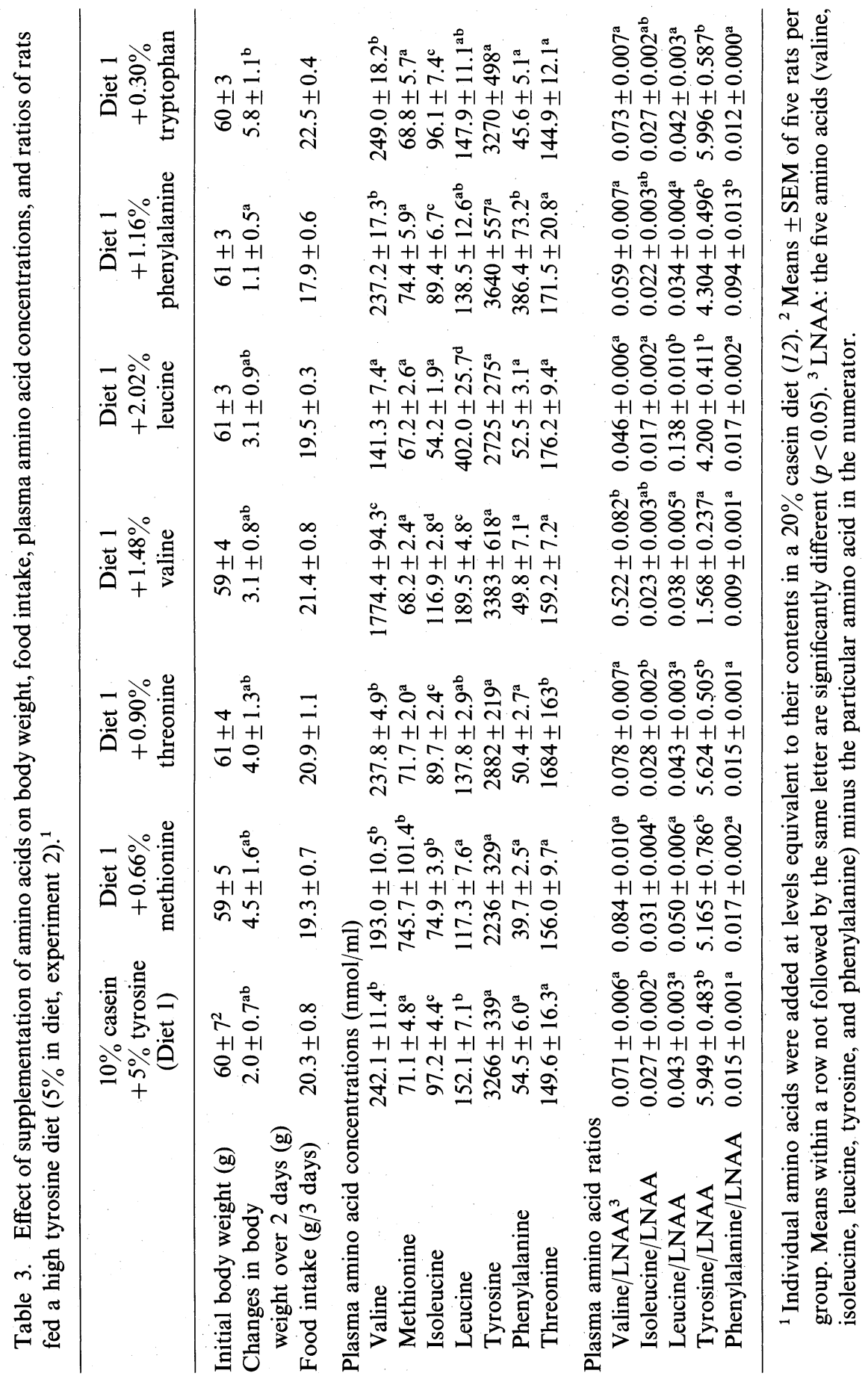




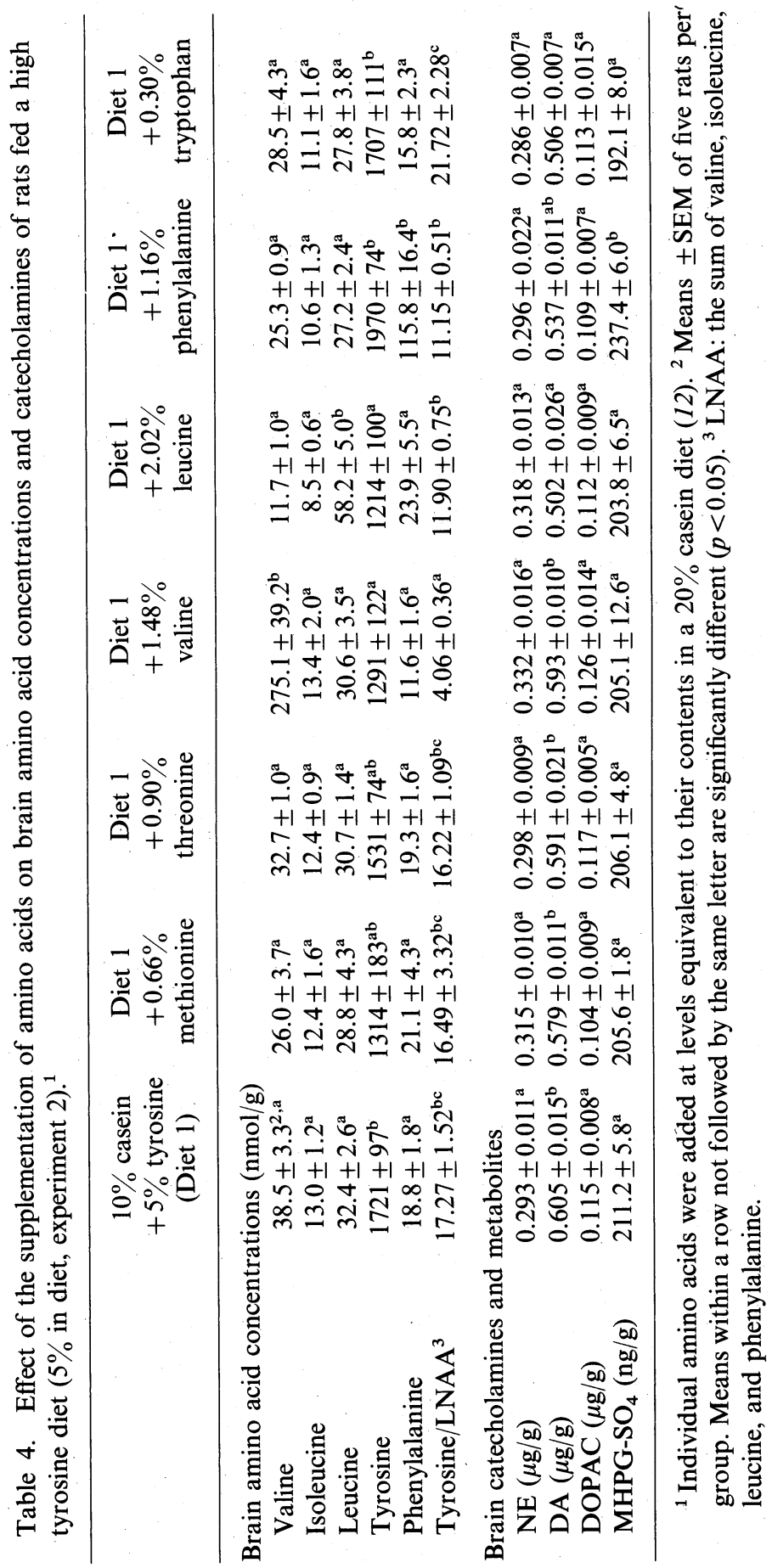

Vol. 31, No. 5, 1985 
plasma and brain were significantly enhanced with or without tyrosine. In the case of the $5 \%$ or $10 \%$ casein diet, excess tyrosine decreased the concentrations of brain amino acids, but with the $30 \%$ casein diet, the concentrations of branched-chain amino acids did not change from that with or without tyrosine. On the other hand, when rats were fed a $5 \%$ tyrosine diet with increasing amounts of casein, the tyrosine ratios (tyrosine/LNAA) were decreased stepwise in plasma $(9.1 \rightarrow 4.5 \rightarrow 1.2)$ and brain $(17.0 \rightarrow 11.6 \rightarrow 2.7)$, accompanied by a decrease of $\mathrm{MHPG}^{-\mathrm{SO}_{4}}$ in brain (Tables 1 and 2). The contents of NE in the brain of rats fed a high tyrosine diet were significantly increased as compared with those of each control group. The contents of DA and DOPAC in the brain were almost the same in each group (Table 2).

\section{Effect of individual amino acids on tyrosine toxicity}

When rats were fed a high tyrosine diet, the further supplementation of methionine, threonine, or tryptophan tended to improve body weight gains, but phenylalanine supplementation tended to adversely affect weight gains (Table 3). The concentrations and ratios per LNAA of the diet supplemented amino acid in plasma were significantly increased. The tyrosine ratio in plasma of rats fed a high tyrosine diet supplemented with valine was significantly decreased as compared with those of other supplemented groups (Table 3). When rats were fed the $10 \%$ casein diet containing excess tyrosine supplemented with large neutral amino acids such as methionine, threonine, valine, or leucine, the contents in brain tyrosine tended to decrease or significantly decreased, but in the case of phenylalanine supplementation, the brain tyrosine content was further increased. Brain catecholamines and metabolites were not greatly different in these groups (Table 4).

\section{Effect of the supplementation of methionine and threonine on tyrosine toxicity}

The supplementation of methionine and threonine to the high tyrosine diet did not improve the body weight gains and food intake for 2-3 days, because of the short-term observation period. Almost all large neutral amino acids in plasma tended to decrease or significantly decreased upon the supplementation of both methionine and threonine as compared with those in rats fed a high tyrosine diet. Tyrosine ratios in plasma were also significantly decreased from 7.2 to 4.0 (Table 5). Upon the supplementation of $5 \%$ tyrosine to the $10 \%$ casein diet, the contents of branched-chain amino acids and phenylalanine in the brain significantly decreased (Table 6). The extreme enhancement of brain tyrosine or tyrosine ratios caused by the supplementation of tyrosine to the $10 \%$ casein diet was significantly reduced by the further supplementation of methionine and threonine (Table 6). The increase of brain $\mathrm{MHPG}-\mathrm{SO}_{4}$ caused by the excess tyrosine diet was significantly reduced by methionine and threonine supplementation. 
Table 5. Effect of the supplementation of methionine and threonine on body weight, food intake, plasma amino acid concentrations, and ratios in rats fed a high tyrosine diet $(5 \%$ in diet, experiment 3$)$.

\begin{tabular}{|c|c|c|c|c|}
\hline & $10 \%$ casein & $\begin{array}{l}10 \% \text { casein } \\
+5 \% \text { tyrosine }\end{array}$ & $\begin{array}{c}10 \% \text { casein } \\
+0.66 \% \\
\text { methionine } \\
+0.90 \% \\
\text { threonine }\end{array}$ & $\begin{array}{c}10 \% \text { casein } \\
+5 \% \text { tyrosine } \\
+0.66 \% \\
\text { methionine } \\
+0.90 \% \\
\text { threonine }\end{array}$ \\
\hline Initial body weight (g) & $71 \pm 5^{1}$ & $71 \pm 4$ & $70 \pm 4$ & $68 \pm 2$ \\
\hline $\begin{array}{l}\text { Changes in body } \\
\text { weight over } 2 \text { days (g) }\end{array}$ & $5.2 \pm 0.5^{\mathrm{ab}}$ & $2.7 \pm 0.9^{\mathrm{a}}$ & $7.2 \pm 1.4^{b}$ & $2.1 \pm 0.9^{\mathrm{a}}$ \\
\hline Food intake ( $\mathrm{g} / 3$ days) & $24.3 \pm 1.0^{\mathrm{a}}$ & $21.6 \pm 0.8^{\mathrm{a}}$ & $24.7 \pm 0.9^{\mathrm{a}}$ & $21.4 \pm 0.9^{\mathrm{a}}$ \\
\hline \multicolumn{5}{|c|}{ Plasma amino acid concentrations ( $\mathrm{nmol} / \mathrm{ml})$} \\
\hline Valine & $214.4 \pm 11.8^{\mathrm{a}}$ & $256.8 \pm 27.2^{\mathrm{ab}}$ & $308.2 \pm 14.4^{\mathrm{b}}$ & $221.2 \pm 28.0^{\mathrm{ab}}$ \\
\hline Methionine & $67.0 \pm 3.2^{\mathrm{a}}$ & $76.6 \pm 9.6^{\mathrm{a}}$ & $869.6 \pm 49.0^{\mathrm{c}}$ & $631.2 \pm 40.2^{\mathrm{b}}$ \\
\hline Isoleucine & $77.2 \pm 5.6^{\mathrm{a}}$ & $86.2 \pm 8.2^{\mathrm{a}}$ & $87.4 \pm 5.6^{\mathrm{a}}$ & $51.0 \pm 6.6^{\mathrm{a}}$ \\
\hline Leucine & $133.0 \pm 10.6^{\mathrm{b}}$ & $143.4 \pm 12.4^{\mathrm{b}}$ & $136.0 \pm 7.4^{b}$ & $73.8 \pm 12.0^{\mathrm{a}}$ \\
\hline Tyrosine & $115.0 \pm 13.0^{\mathrm{a}}$ & $3602 \pm 322^{c}$ & $116.2 \pm 7.6^{\mathrm{a}}$ & $1565 \pm 66^{\mathrm{b}}$ \\
\hline Phenylalanine & $66.2 \pm 8.6^{\mathrm{b}}$ & $49.8 \pm 4.8^{\mathrm{ab}}$ & $52.6 \pm 3.8^{\mathrm{ab}}$ & $29.4 \pm 3.6^{\mathrm{a}}$ \\
\hline Threonine & $240.8 \pm 25.8^{\mathrm{a}}$ & $220.4 \pm 24.2^{\mathrm{a}}$ & $2830 \pm 96^{c}$ & $1684 \pm 78^{b}$ \\
\hline \multicolumn{5}{|l|}{ Plasma amino acid ratios } \\
\hline Valine/LNAA ${ }^{2}$ & $0.599 \pm 0.045^{\mathrm{b}}$ & $0.061 \pm 0.003^{\mathrm{a}}$ & $0.793 \pm 0.046^{\mathrm{c}}$ & $0.142 \pm 0.016^{\mathrm{a}}$ \\
\hline Isoleucine/LNAA & $0.149 \pm 0.004^{b}$ & $0.020 \pm 0.001^{\mathrm{a}}$ & $0.142 \pm 0.007^{b}$ & $0.029 \pm 0.004^{\mathrm{a}}$ \\
\hline Leucine/LNAA & $0.286 \pm 0.013^{\mathrm{c}}$ & $0.034 \pm 0.001^{\mathrm{a}}$ & $0.241 \pm 0.011^{\mathrm{b}}$ & $0.043 \pm 0.007^{\mathrm{a}}$ \\
\hline Tyrosine/LNAA & $0.214 \pm 0.010^{\mathrm{a}}$ & $7.212 \pm 0.255^{\mathrm{c}}$ & $0.198 \pm 0.007^{\mathrm{a}}$ & $3.997 \pm 0.490^{b}$ \\
\hline Phenylalanine/LNAA & $0.112 \pm 0.010^{\mathrm{c}}$ & $0.012 \pm 0.001^{\mathrm{a}}$ & $0.081 \pm 0.005^{\mathrm{b}}$ & $0.017 \pm 0.001^{\mathrm{a}}$ \\
\hline
\end{tabular}

${ }^{1}$ Means \pm SEM of six rats per group. Means within a row not followed by the same letter are significantly different $(p<0.05) .{ }^{2}$ LNAA: the five amino acids (valine, isoleucine, leucine, tyrosine, and phenylalanine) minus the particular amino acid in the numerator.

\section{DISCUSSION}

It has been shown that when rats were fed a low protein-high tyrosine diet, reduction of growth and food intake, eye and paw lesions, and high mortality occurred (1-4). Also, tyrosine toxicity is significantly influenced by the content and source of dietary protein, that is, tyrosine toxicity can be overcome by increasing the protein content in the diet (3). On the other hand, tyrosine is substrate of protein synthesis and also catecholamine synthesis. The synthesis of NE and DA increases in physiologically active and frequently-firing neurons(27) when more tyrosine is made available to the brain. These effects have the ability to lower blood pressure in certain types of hypertension (28), to treat clinical depression (29), to lower plasma

Vol. 31, No. 5, 1985 
Table 6. Effect of the supplementation of methionine and threonine on brain amino acid concentrations and catecholamines in rats fed a high tyrosine diet $(5 \%$ in diet, experiment 3).

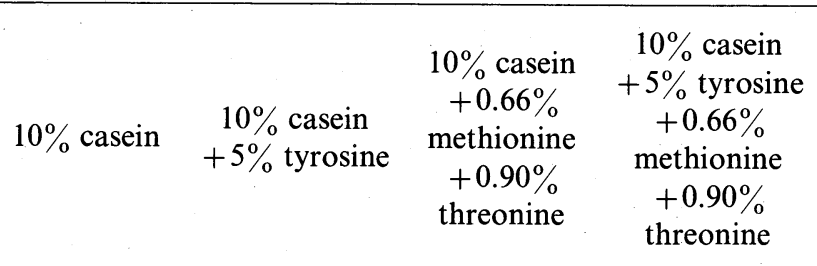

\begin{tabular}{|c|c|c|c|c|}
\hline \\
\hline Valine & $71.9 \pm 3.5^{1, \mathrm{~b}}$ & $43.1 \pm 2.1^{\mathrm{a}}$ & $68.6 \pm 7.8^{\mathrm{b}}$ & Brain amino acid concentrations $(\mathrm{nmol} / \mathrm{g})$ \\
\hline Isoleucine & $25.1 \pm 1.6^{\mathrm{b}}$ & $17.1 \pm 0.7^{\mathrm{a}}$ & $23.0 \pm 1.7^{b}$ & $15.9 \pm 1.1^{\mathrm{a}}$ \\
\hline Leucine & $66.2 \pm 2.1^{\mathrm{b}}$ & $48.5 \pm 0.8^{\mathrm{a}}$ & $60.6 \pm 4.0^{\mathrm{b}}$ & $41.2 \pm 3.1^{\mathrm{a}}$ \\
\hline Tyrosine & $70.3 \pm 7.1^{\mathrm{a}}$ & $1578 \pm 100^{\mathrm{c}}$ & $72.0 \pm 4.0^{\mathrm{a}}$ & $1016 \pm 67^{b}$ \\
\hline Phenylalanine & $57.0 \pm 6.1^{\mathrm{b}}$ & $27.5 \pm 1.0^{\mathrm{a}}$ & $44.7 \pm 5.8^{\mathrm{a}}$ & $25.7 \pm 1.6^{\mathrm{a}}$ \\
\hline Threonine & $397.0 \pm 28.7^{\mathrm{a}}$ & $231.1 \pm 22.4^{a}$ & $1881+121^{\mathrm{c}}$ & $1044+203^{b}$ \\
\hline Tyrosine/LNAA ${ }^{2}$ & $0.326 \pm 0.033^{\mathrm{a}}$ & $11.64 \pm 0.84^{\mathrm{c}}$ & $0.361+0.019^{\mathrm{a}}$ & $8.406+0.879$ \\
\hline
\end{tabular}

Brain catecholamines and metabolites
$\mathrm{NE}(\mu \mathrm{g} / \mathrm{g})$
$0.257+0.010^{\circ}$
$0.273 \pm 0.013^{\mathrm{a}} \quad 0.260 \pm 0.008^{\mathrm{a}}$
$0.272 \pm 0.014^{\mathrm{a}}$
$\mathrm{DA}(\mu \mathrm{g} / \mathrm{g})$
$0.561 \pm 0.020^{\mathrm{a}}$
$0.565 \pm 0.017^{\mathrm{a}} \quad 0.560 \pm 0.019^{\mathrm{a}}$
$0.593 \pm 0.016^{\mathrm{a}}$
DOPAC $(\mu \mathrm{g} / \mathrm{g})$
$0.090 \pm 0.007^{\mathrm{ab}}$
$0.092 \pm 0.006^{\mathrm{ab}} 0.078 \pm 0.003^{\mathrm{a}}$
$0.100 \pm 0.004^{\mathrm{b}}$
MHPG-SO $_{4}$ (ng/g)
$139.5 \pm 3.8^{\mathrm{ab}}$
$158.2 \pm 8.9^{\mathrm{b}}$
$128.0 \pm 4.2^{\mathrm{a}}$
$131.1 \pm 4.8^{\mathrm{a}}$

\begin{abstract}
${ }^{1}$ Means \pm SEM of six rats per group. Means within a row not followed by the same letter are significantly different $(p<0.05) .{ }^{2}$ LNAA: the sum of valine, isoleucine, leucine, and phenylalanine.
\end{abstract}

prolactin levels in hyperprolactinemia (30), to enhance subjective vigor (especially in older people)(31), and even to raise blood pressure in shock(32). Therefore, I investigated the correlation between tissue tyrosine concentrations and tyrosine ratios and catecholamines in brain. The concentrations of brain tyrosine were directly correlated with those of tyrosine and tyrosine ratios in plasma. When rats were fed a high tyrosine diet ( $5 \%$ tyrosine in diet) with increasing amounts of dietary protein, tyrosine toxicity (reduction of body weight gain and food intake) was directly correlated with brain tyrosine and $\mathrm{MHPG}-\mathrm{SO}_{4}$ because of the stepwise decrease of brain tyrosine and $\mathrm{MHPG}-\mathrm{SO}_{4}$ levels (Tables 1 and 2). These data suggest that dietary protein may change the tyrosine ratio in plasma and also decrease the uptake of tyrosine through the blood-brain barrier because of the enhanced uptake of other amino acids induced by the digestion of dietary proteins.

When rats were fed the $10 \%$ casein diet containing excess tyrosine with further supplementation of methionine, threonine, valine, or leucine (at levels equivalent to the content in $20 \%$ casein), the contents brain tyrosine tended to decrease or significantly decreased. However, in the case of phenylalanine supplementation, 
tyrosine toxicity was enhanced and brain tyrosine was also increased (Tables 3 and 4). This effect of phenylalanine is consistent with Muramatsu's data (12). According to their report (12), the addition of phenylalanine to the high tyrosine diet enhanced the adverse effects (body weight loss, cataract formation, and high mortality), and all animals died within 2 weeks. The reason for this adverse effect of phenylalanine is not known, but it may be that the action of phenylalanine inhibits tyrosine hydroxylase in the brain (33), and therefore tyrosine would accumulate in the brain and its toxicity would be accelerated.

Methionine and threonine are the most limiting amino acids in casein and, under the conditions of a protein-free or low-protein diet, these amino acids are also limited in the rat $(34,35)$. The beneficial effects of the supplementation of methionine and threonine to the high tyrosine diet have been shown in tyrosine toxicity in rats $(13,14)$. Therefore, in relation to methionine and threonine action, I determined the amino acid, catecholamines and metabolites in the brain. When rats were fed a $10 \%$ casein diet containing tyrosine with both methionine and threonine for 3 days, the enhancement of tyrosine, tyrosine ratios, and $\mathrm{MHPG}-\mathrm{SO}_{4}$ in the brain induced by excess tyrosine were significantly reduced (Table 6). The supplementation of dietary protein or methionine and threonine may improve the nutritional state (the increase of tyrosine utilization), because methionine and threonine are the most limiting amino acids in casein and also may inhibit the uptake of tyrosine into the brain via the blood-brain barrier. These results also suggest that effects of tyrosine toxicity such as growth retardation or external pathological lesions may be due to the accelerated NE-turnover in the brain accompanied by the enhancement of brain tyrosine concentration.

On the other hand, there are many papers concerned with tyrosine catabolism $(14,36,37)$. When rats were fed a high tyrosine diet, because the concentrations of tyrosine in tissues were decreased by the addition of protein or methionine and threonine, the increased rate of tyrosine catabolism was considered. One possibility is the enhanced activity of 4-hydroxyphenylpyruvate hydroxylase [EC 1.13.11.27], which may be the rate-limiting enzyme of tyrosine catabolism $(14,36,37)$. A second possibility is the enhancement of tyrosine excretion in urine or its utilization by plasma and liver protein synthesis. Therefore, these results suggest that the addition of dietary proteins or methionine and threonine decreases the tyrosine concentrations in body fluids (including the brain), improves the nutritional quality by the elevation of tyrosine oxidation capacity or of the utilization of tyrosine, and overcomes toxicity.

I wish to thank Dr. R. J. Wurtman of the Massachusetts Institute of Technology for helpful discussion (the studies were largely done at MIT) and for the opportunity to be a fellow of the Center for Brain Sciences and Metabolism Charitable Trust. 


\section{REFERENCES}

1) Sauberlich, H. E. (1961): Studies on the toxicity and antagonism of amino acids for weanling rats. $J$. Nutr., 75, 61-72.

2) Harper, A. E., Becker, R. V., and Stucki, W. P. (1966): Some effects of excessive intakes of indispensable amino acids. Proc. Soc. Exp. Biol. Med., 121, 695-699.

3) Muramatsu, K., Odagiri, H., Morishita, S., and Takeuchi, H. (1971): Effect of excess levels of individual amino acids on growth of rats fed casein diets. J. Nutr., 101, 1117 1125.

4) Muramatsu, K., Takeuchi, H., Funaki, Y., and Chisuwa, A. (1972): Influence of protein source on growth-depressing effect of excess amino acids in young rats. Agric. Biol. Chem., 36, 1269-1276.

5) Muramatsu, K., Takei, M., and Nakamura, K. (1975): Effect of dietary protein on tyrosine toxicity in the rat. J. Nutr., 105, 439-446.

6) Sullivan, M. X., Hess, W. C., and Sebrell, W. H. (1932): Studies on the biochemistry of sulphur. XII. Preliminary studies on amino-acid toxicity and amino-acid balance. U.S. Public. Health Rep., 47, 75-83.

7) Martin, G. J., and Hueper, W. C. (1943): Biochemical lesions produced by diets high in tyrosine. Arch. Biochem., 1, 435-438.

8) Benton, D. A., Harper, A. E., Spivey, H. E., and Elvehjem, C. A. (1956): Phenylalanine as an amino acid antagonist for the rat. Arch. Biochem. Biophys., 60, 156-163.

9) Alam, S. Q., Becker, R. V., Stucki, W. P., Rogers, Q. R., and Harper, A. E. (1966): Effect of threonine on the toxicity of excess tyrosine and cataract formation in the rat. $J$. Nutr., 89, 91-96.

10) Alam, S. Q., Rogers, Q. R., and Harper, A. E. (1966): Effect of tyrosine and threonine of free amino acids in plasma, liver, muscle, and eye in the rat. J. Nutr., 89, 97-105.

11) Alam, S. Q., Boctor, A. M., Rogers, Q. R., and Harper, A. E. (1967): Some effects of amino acids and cortisol on tyrosine toxicity in the rat. J. Nutr., 93, 317-323.

12) Muramatsu, K., Arito, T., and Tsuda, H. (1976): Effect of individual amino acid supplements on the toxicity of excess tyrosine in rats. J. Nutr. Sci. Vitaminol., 22, 397403.

13) Yamamoto, Y., Katayama, H., and Muramatsu, K. (1976): Beneficial effect of methionine and threonine supplements on tyrosine toxicity in rats. J. Nutr. Sci. Vitaminol., 22, 467-475.

14) Yamamoto, Y., Toyoshima, R., and Muramatsu, K. (1979): Effect of additional protein or methionine and threonine on tyrosine catabolism in rats fed diets high in tyrosine. Agric. Biol. Chem., 43, 2585-2590.

15) Kapatos, G., and Zigmond, M. (1977): Dopamine biosynthesis from L-tyrosine and L-phenylalanine in rat brain synaptosomes: preferential accumulation of precursors. J. Neurochem., 28, 1109-1119.

16) Nagatsu, T., Levitt, M., and Udenfriend, S. (1964): Tyrosine hydroxylase: the initial step in norepinephrine biosynthesis. J. Biol. Chem., 239, 2910-2917.

17) Alonso, R., Agharanya, J. C., and Wurtman, R. J. (1980): Tyrosine loading enhances catecholamine excretion by rats. J. Neural. Trans., 49, 31-43.

18) Agharanya, J. C., and Wurtman, R. J. (1982): Studies on the mechanism by which tyrosine raises urinary catecholamines. Biochem. Pharmacol., 31, 3577-3580.

19) Agharanya, J. C., Alonso, R., and Wurtman, R. J. (1981): Changes in catecholamine excretion after short-term tyrosine ingestion in normally fed human subjects. Am. J. Clin. Nutr., 34, 82-87. 
20) Alonso, R., Gibson, C. J., Wurtman, R. J., Agharanya, J. C., and Prieto, L. (1982): Elevation of urinary catecholamines and their metabolites following tyrosine administration in humans. Biol. Psych., 17, 781-790.

21) Gibson, C. J., Watkins, C. J., and Wurtman, R. J. (1983): Tyrosine administration enhances dopamine synthesis and release in light-activated rat retina. J. Neural Trans., 56, 153-160.

22) Gibson, C. J., Watkins, C. J., and Wurtman, R. J. (1982): The effects of tyrosine and other nutrients on neurotransmitter synthesis in the brain and retina. Retina, 2, 332340.

23) Pardridge, W. M. (1977): Regulation of amino acid availability to the brain, in Nutrition and the Brain, Vol. 1, ed. by Wurtman, R. J., and Wurtman, J. J., Raven Press, New York, pp. 141-204.

24) Felice, L. J., Felice, J. D., and Kissinger, P. T. (1978): Determination of catecholamines in rat brain parts by reverse-phase ion-pair chromatography. J. Neurochem., 31, 14611465.

25) Waalkes, T. P., and Udenfriend, S. (1957): A fluorimetric method for the estimation of tyrosine in plasma and tissues. J. Lab. Clin. Med., 50, 733-736.

26) Duncan, D. B. (1957): Multiple-range tests for correlated and heteroscedastic means. Biometrics, 13, 164-176.

27) Wurtman, R. J. (1982): Nutrients that modify brain function. Sci. Am., 246, 50-59.

28) Sved, A. F., Fernstrom, J. D., and Wurtman, R. J. (1979): Tyrosine administration reduces blood pressure and enhances brain norepinephrine release in spontaneously hypertensive rats. Proc. Natl. Acad. Sci. USA., 76, 3511-3514.

29) Gelenberg, A. J., Wojcik, J. D., Growdon, J. H., Sved, A. F., and Wurtman, R. J. (1980): Tyrosine for the treatment of depression. Am. J. Psych., 137, 622-623.

30) Sved, A. F., Fernstrom, J. D., and Wurtman, R. J. (1979): Tyrosine administration decreases serum prolactin levels in chronically reserpinized rats. Life Sci., 25, 12931300 .

31) Leathwood, P. O., and Pollet, P. (1983): Diet induced mood changes in normal population. J. Psychiatr. Res., 17, 147-154.

32) Conlay, L. A., Maher, T. J., and Wurtman, R. J. (1981): Tyrosine increases blood pressure in hypertensive rats. Science, 212, 559-560.

33) Gibson, C. J., and Wurtman, R. J. (1977): Physiological control of brain catechol synthesis by brain tyrosine concentration. Biochem. Pharmacol., 26, 1137-1142.

34) Yokogoshi, H., and Yoshida, A. (1976): Some factors affecting the nitrogen sparing action of methionine and threonine in rats fed a protein free diet: J. Nutr., 106, 48-57.

35) Yokogoshi, H., and Yoshida, A. (1981): Sequence of limiting amino acids for the utilization of endogenous amino acids in rats fed a protein-free diet. Nutr. Rep. Int., 23, 517-523.

36) Yamamoto, Y., Toyoshima, R., and Muramatsu, K. (1979): Response of liver tyrosinecatabolizing enzymes in rats fed high tyrosine diets. Agric. Biol. Chem., 43, 585-590.

37) Ip, C. C. Y., and Harper, A. E. (1973): Effects of dietary protein content and glucagon administration on tyrosine metabolism and tyrosine toxicity in the rat. J. Nutr., 103, 1594-1607. 